\title{
Inovasi Mesin Duta Baru sebagai Pengaduk dan Pencetak Kue Kembang Waru di UMKM Kotagede Yogyakarta
}

\author{
Duta Baru Machine Innovation as Mixer and Molder of Kembang Waru Cake \\ at MSME Kotagede Yogyakarta
}

\begin{tabular}{|c|c|}
\hline $\begin{array}{l}\text { Nia A’yunin }{ }^{\mathbf{1}} \text {, Firdaus Fitri }{ }^{\mathbf{2}} \text {, \& Febbyola Raflyani }{ }^{\mathbf{3}} \\
{ }^{123} \text { Fakultas Teknik Industri, Universitas Pembangunan Nasional "Veteran" } \\
\text { Yogyakarta, Kota Yogyakarta, Indonesia } \\
\text { ayunin26@gmail.com }\end{array}$ & $\begin{array}{r}\text { Riwayat naskah: } \\
\text { Diterima: } 11 \text { Desember } 2020 \\
\text { Disetujui: } 6 \text { Maret } 2021 \\
\text { Diterbitkan: } 19 \text { Maret } 2021\end{array}$ \\
\hline
\end{tabular}

Abstract: Kembang Waru is one of the traditional cakes popular in Kotagede, Yogyakarta. The cake has a shape like a Waru leaf. One of the micro, small, medium enterprises (MSMEs/UMKM) that produces Kembang Waru cake is the one owned by Mr. Basiran Hargito. The process of making Kembang Waru cake starts with stirring the dough, pouring the dough into a mold, and baking process in an oven that uses charcoal. Based on observations, the problems occurred were the ineffectiveness and inefficiency of the kneading and pouring process. It causes workers to feel tired easily, which can reduce productivity. Based on these problems, the solution is making Duta Baru machines with an ergonomics-anthropometric approach. The purpose of making machines is to assist workers in the process of mixing and storing the dough in the mold. The approach aims to determine the dimensions of the machine according to the body size of the workers in the MSME. Besides, the aim of designing the Duta Baru machine supports the global agenda, namely Sustainable Development Goals, which can make the industry better. The machine was able to increase the productivity rate by $25 \%$.

Keywords: anthropometry-ergonomics; machine innovation; MSME; productivity.

Abstrak: Kue kembang waru merupakan makanan khas yang berasal dari Kotagede, Yogyakarta Kue ini dinamakan kembang waru sebab berbentuk seperti bunga waru. Salah satu UMKM yang memproduksi kue Kembang Waru yaitu UMKM milik Bapak Basiran Hargito. Proses pembuatan kue kembang waru mulai dari pengadukan adonan, penuangan adonan dalam cetakan, hingga proses pemanggangan dengan oven yang menggunakan arang. Berdasarkan pengamatan, ditemukan bahwa masalah yang terjadi yaitu ketidakefektifan dan ketidakefisienan proses pengadukan dan penuangan adonan. Hal ini menyebabkan pekerja mengalami kelelahan sehingga dapat menurunkan produktivitas. Berdasarkan permasalahan tersebut, maka dilakukan perancangan inovasi mesin Duta Baru dengan pendekatan ergonomi-antropometri. Pembuatan mesin bertujuan untuk membantu pekerja dalam proses pengadukan dan penuangan adonan dalam cetakan. Pendekatan ergonomi-antropometri bertujuan untuk mengetahui dimensi mesin sesuai dengan ukuran tubuh pekerja yang ada di UMKM tersebut. Selain itu, tujuan perancangan mesin Duta Baru mendukung agenda dunia yaitu Sustainable Development Goals, yang dapat membuat perindustrian menjadi lebih baik.Pembuatan mesin mampu meningkatkan tingkat produktivitas sebesar $25 \%$.

Kata kunci: antropometri-ergonomi; inovasi mesin; produktivitas; UMKM. 


\section{Pendahuluan}

UMKM (Usaha Mikro Kecil Menengah) merupakan usaha milik perseorangan atau badan usaha perorangan yang memiliki peranan penting dalam laju perekonomian negara Indonesia, dari sisi lapangan kerja ataupun jumlah usahanya. Di tahun 1992-2000, UMKM menjadi penyelamat perekonomian Indonesia pada masa krisis. Data statistik menunjukan jumlah UMKM mendekat angka 99,98\% dari total unit usaha di Indonesia dengan kontribusi sebesar 56\% dari total PDB di Indonesia. Hal tersebut memperlihatkan bahwa signifikansi peran UMKM bagi pemerataan ekonomi Indonesia termasuk tinggi. (Leiwakabessy \& Lahallo, 2018). Pada bidang perekonomian, UMKM turut serta dalam upaya meningkatkan taraf hidup di masyarakat sekitarnya (Tanan \& Damayanti, 2020). Namun, sampai saat ini masih terdapat beragam persoalan terkait dengan rendahnya kualitas sumber daya yang salah satunya dapat menyebabkan tingkat produktivitas pada UMKM masih tergolong rendah. Provinsi Daerah Istimewa Yogyakarta memiliki jumlah UMKM sebanyak 220.771 unit dengan berbagai bidang yaitu fashion, kuliner, pendidikan, otomotif, agrobisnis, teknologi informasi, serta perdagangan dan jasa. Salah satu UMKM bidang kuliner di Yogyakarta adalah usaha kue tradisional bernama kue Kembang Waru milik Bapak Basiran Hargito. Kembang waru merupakan kue tradisional dengan ciri khas berbentuk bunga berkelopak delapan dengan tepung terigu sebagai bahan utamanya. Usaha milik Bapak Basiran Hargito ini sudah berdiri sejak tahun 1983 dengan memproduksi kurang lebih 1.000 hingga 1.500 biji kue kembang waru setiap harinya. Hasil produksinya dipasarkan dengan harga Rp1.500,00 per bijinya. Bapak Basiran sampai saat ini sangat menjaga keaslian kue kembang waru, hal tersebut dapat dilihat dari proses produksi yang sangat tradisional serta kemasan produk yang sederhana.

Proses pembuatan kembang waru dimulai dari pembuatan adonan yaitu dengan mencampurkan tepung terigu, telur, garam, mentega, dan gula sebagai bahan utama, serta fermipan sebagai pengembang. Lalu, menuangkan adonan ke dalam cetakan berbentuk bunga waru dengan menggunakan centong. Selanjutnya, adonan dipanggang dengan menggunakan arang yang terdapat pada bagian atas dan bawah pemanggang. Berdasarkan observasi, proses tidak efektif dan efisien ditemukan pada proses pengadukan dan penuangan adonan. Proses pengadukan dilakukan secara manual sehingga menyebabkan kelelahan bagi pekerja. Selain itu, pekerja harus menuangkan adonan yang dilakukan satu per satu untuk masing-masing cetakan sehingga memakan waktu produksi yang lama. Proses penuangan adonan berlangsung kurang lebih 5 menit setiap 15 biji kue kembang waru.

Berdasarkan uraian di atas, proses pengadukan dan pencetakan adonan merupakan permasalahan utama pada proses pembuatan kue kembang waru di UMKM milik Bapak Basiran Hargito. Hal tersebut dikarenakan proses pengadukan dilakukan secara manual menyebabkan kelelahan pekerja serta proses penuangan adonan harus dilakukan satu per satu pada masingmasing cetakan. Proses yang dilakukan secara manual ini dapat menyebabkan penurunan produksi secara bertahap akibat kelelahan yang dialami pekerja. Faktor-faktor yang mempengaruhi terjadi kelelahan kerja adalah adanya monotoni pekerjaan; adanya intensitas, durasi kerja, mental dan fisik yang tidak proporsional; faktor lingkungan kerja, cuaca, kebisingan; faktor mental seperti tanggung jawab, ketegangan dan konflik-konflik yang berkaitan; serta adanya penyakit-penyakit, kesakitan, dan nutrisi yang tidak memadai (Hendrawan, Sucahyowati, \& Laras, 2020). Pada proses penuangan adonan satu persatu ke masing-masing cetakan dapat 
menyebabkan penambahan waktu produksi. Waktu produksi ini sangat berkaitan pada ketepatan waktu sampai ke konsumen. Dengan membuat waktu produksi yang minimal maka akan membuat produk cepat sampai ke konsumen, hal tersebut dapat meningkatkan kepuasan konsumen. Berdasarkan wawancara dengan Bapak Basiran, UMKM kue kembang waru ini selalu mendapat pesanan untuk acara-acara besar dalam jumlah yang tidak sedikit.

Dari permasalahan tersebut, penelitian ini akan merancang sebuah mesin inovasi untuk membantu UMKM dalam mempersingkat proses pengadukan dan pencetakan adonan kue secara efektif dan efisien. Pendekatan dalam perancangan yang digunakan adalah pendekatan ergonomi antropometri dengan hasil yang dicapai dapat menurunkan waktu proses produksi serta meningkatkan produktivitas dalam pembuatan kue kembang waru. Pendekatan antropometri merupakan studi yang berkaitan dengan pengukuran tubuh manusia, yang dapat digunakan untuk pertimbangan merancang produk ataupun tempat kerja yang melibatkan manusia (Husein, Kholil, \& Sarsono, 2009). Pembuatan perancangan alat ini memiliki pertimbangan dapat mengakomodasi populasi terbesar yang akan menggunakan hasil rancangan. Manfaat dari penerapan ergonomi yaitu dapat membantu dalam memperbaiki performansi pekerja, mengurangi waktu yang terbuang sia-sia, meminimalkan kerusakan peralatan yang disebabkan oleh kesalahan manusia, dan memperbaiki kenyamanan pada sistem yang digunakan. Oleh karena mesin yang dirancang ini memiliki proyeksi sedemikian rupa, peneliti menyebutnya dengan nama "Duta Baru", karena dapat menjadi model pembaruan dalam proses kerja di UMKM ini.

\section{Metode Penelitian}

Untuk memecahkan permasalahan pada penelitian terlibat (engaged research) dengan merancang mesin inovasi ini, digunakan metode Ergonomi Antropometri. Ergonomi merupakan ilmu yang mempelajari interaksi manusia, alat, dengan sistem kerja. Ergonomi berkaitan dengan optimasi, efisiensi, kesehatan, keselamatan, dan kenyamanan manusia di lingkungan tempat manusia beraktivitas. Selain itu, ilmu ergonomi mempelajari mengenai sistem antara manusia, fasilitas kerja, dan lingkungan yang berinteraksi dengan tujuan menyesuaikan suasana kerja dengan manusia. Tujuan dari penerapan ergonomi yaitu untuk meningkatkan kesejahteraan fisik dan mental serta sosial, dan menciptakan keseimbangan rasional dari berbagai aspek teknis (Putra, Vidawati, Melati, Raflyani, Ilfiana, \& Wibawa, 2019). Perancangan merupakan suatu tahapan dalam membuat konsep atau desain baru dengan tujuan menyelesaikan permasalahan yang dihadapi.

Antropometri berasal dari kata antropo yaitu manusia dan metri yang berarti ukuran. Antropometri merupakan kumpulan data numerik yang berhubungan dengan karakteristik tubuh manusia meliputi ukuran, bentuk, fisik, dan kekuatan sebagai penerapan dalam perancangan desain. Antropometri juga disebut sebagai pengetahuan yang mempelajari mengenai dimensi tubuh manusia (Norfiza \& Infi, 2011). Perancangan produk dipertimbangkan dengan menggunakan Antropometri yang disesuaikan dengan sistem kerja. Ukuran yang digunakan dalam antropometri merupakan standar rata-rata/kurva normal yang diaplikasikan dalam perancangan peralatan kerja, perancangan area kerja, perancangan produk, dan perancangan lingkungan kerja fisik. Data-data antropometri yang digunakan sebagai dimensi perancangan produk pada penelitian ini yaitu Lebar Bahu (LB), Jangkauan Tangan ke Depan (JTD), dan 
Tinggi Siku Berdiri (TSB). Dimensi akan disesuaikan dengan perhitungan melalui persentil yang akan dipilih.

Persentil pada pendekatan antropometri merupakan sekumpulan daya yang dibagi menjadi 100 bagian yang sama. Persentil memiliki 99 pembagi berturut-turut yang dinamakan persentil pertama, persentil kedua, hingga persentil ke-99. Penjelasan tersebut didukung oleh Riduwan (2009) yang menyatakan bahwa persentil merupakan nilai yang membagi menjadi 100 bagian yang sama. Persentil juga dapat dikatakan sebagai nilai sekumpulan data yang dibagi menjadi seratus bagian yang sama (Andi, 2007). Karena mesin Duta Baru ini dirancang untuk menyelesaikan permasalahan yang ada pada salah satu UMKM produksi kue kembang waru di Kotagede, utamanya untuk meningkatkan produktivitas, maka penggunaan metode ergonomi antropometri dapat dilaksanakan dengan efektif (Fitri, Raflyani, A’yunin, \& Prabuningrum, 2020).

\section{Pelaksanaan}

Penelitian dan pengabdian masyarakat dilakukan sejak Juni 2019 hingga Desember 2019. Pengabdian ini dilakukan melalui beberapa tahapan. Tahap pertama yaitu melakukan koordinasi dengan mitra untuk mengidentifikasi permasalahan-permasalahan yang ada pada mitra terkait.

Tahap kedua yaitu pengambilan data antropometri yang relevan meliputi Lebar Bahu (LB), Jangkauan Tangan ke Depan (JTD), dan Tinggi Siku Berdiri (TSB) dari pekerja. Keterlibatan masyarakat dalam hal ini yaitu mengukur tubuh pekerja, untuk didapatkan data antropometri yang diperlukan. Keikutsertaan pekerja dalam melaksanakan metode penelitian berguna untuk menghasilkan mesin yang ergonomis bagi penggunanya.

Tahap ketiga yaitu merancang mesin dengan memperhatikan data antropometri yang telah diolah. Tahap keempat yaitu fabrikasi mesin dengan menentukan spesifikasi dan komponen mesin secara rinci serta melakukan pembelian komponen yang akan digunakan. Tahap selanjutnya yaitu melakukan uji coba mesin dan evaluasi untuk mengetahui kesesuaian fungsi dengan tujuannya. Apabila terdapat kekurangan pada tahap ini maka dilakukan analisis terhadap kegunaan mesin dan tahap terakhir yaitu publikasi mesin melalui artikel yang diterbitkan pada jurnal ilmiah.

Tahapan-tahapan ini ditunjukkan pada model perancangan pelaksanaan program sehingga dapat dilaksanakan secara sistematis dan terstruktur seperti gambar 1. 


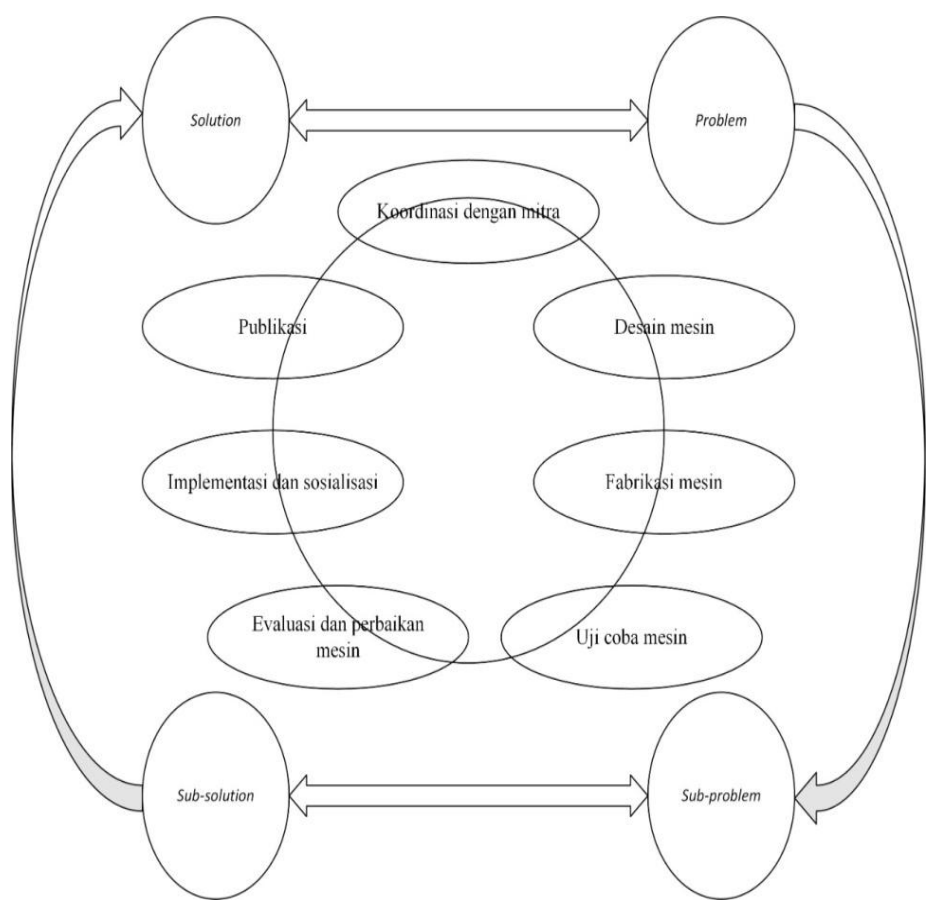

Gambar 1. Tahapan Penelitian

\section{Pengolahan Data}

Data antropometri yang digunakan untuk perancangan mesin ialah Lebar Bahu (LB), Jangkauan Tangan ke Depan (JTD), dan Tinggi Siku Berdiri (TSB). LB dipilih untuk menentukan panjang mesin, JTD dipilih untuk menentukan lebar mesin, dan TSB digunakan untuk menentukan tinggi mesin. Data antropometri ini diukur pada 3 pekerja yang bekerja pada UMKM. Pekerja yang menjadi objek penelitian adalah pekerja yang melakukan pekerjaan mengaduk dan mencetak adonan kembang waru. Data antropometri pada 3 pekerja dapat dilihat pada Tabel 1 berikut ini.

Tabel 1. Data antropometri pekerja

\begin{tabular}{|c|c|c|c|}
\hline Nama Pekerja & LB (cm) & JTD (cm) & TSB (cm) \\
\hline Pekerja 1 & 45 & 70 & 104 \\
\hline Pekerja 2 & 42 & 68 & 99 \\
\hline Pekerja 3 & 45 & 74 & 102 \\
\hline
\end{tabular}

Uji data dilakukan dengan uji kecukupan dan uji keseragaman terlebih dahulu sebelum menentukan hasil ukuran yang didapat melalui perhitungan persentil. Uji kecukupan berguna untuk mengetahui apakah yang digunakan sudah cukup atau belum sedangkan uji keseragaman data berguna untuk mengetahui data yang digunakan sudah seragam atau belum. Uji kecukupan data diketahui dengan mencari nilai N' dan uji keseragaman data berisi perhitungan batas kendali atas (BKA) dan batas kendali bawah (BKB) yang kemudian di gambar grafik uji untuk mengetahui apakah ada data yang keluar batas atau tidak. Perhitungan uji keseragaman data antropometri pada 3 pekerja dapat dilihat pada Tabel 2 berikut ini. 
Inovasi Mesin Duta Baru sebagai Pengaduk dan Pencetak Kue Kembang Waru di UMKM... Nia A'yunin, Firdaus Fitri, \& Febbyola Raflyani

Tabel 2. Uji keseragaman data

\begin{tabular}{|c|c|c|c|}
\hline Pengukuran & BKA & BKB & Hasil \\
\hline LB & 47,46 & 40,54 & Data seragam \\
\hline JTD & 75,38 & 65,95 & Data seragam \\
\hline TSB & 106,7 & 96,63 & Data seragam \\
\hline
\end{tabular}

Dari hasil perhitungan nilai BKA dan BKB terlihat tidak ada data yang keluar dari batas, sebagai contoh data LB terdiri dari $45 \mathrm{~cm}, 42 \mathrm{~cm}$, dan $45 \mathrm{~cm}$, dari 3 data tersebut tidak ada yang melewati batas atas $47.46 \mathrm{~cm}$ dan batas bawah $40.54 \mathrm{~cm}$, maka data LB sudah seragam. Perhitungan uji kecukupan data antropometri pada 3 pekerja dapat dilihat pada Tabel 3 berikut ini. Tingkat kepercayaan yang digunakan pada uji kecukupan data ini ialah 95\% $(\mathrm{K}=2)$ dan derajat ketelitian 5\% $(\mathrm{s}=0,05)$.

Tabel 3. Uji kecukupan data

\begin{tabular}{|c|c|c|c|}
\hline Pengukuran & N & $\mathbf{N}^{\prime}$ & Hasil \\
\hline LB & 3 & 1,65 & Data cukup \\
\hline JTD & 3 & 1,99 & Data cukup \\
\hline TSB & 3 & 0,65 & Data cukup \\
\hline
\end{tabular}

Dari hasil perhitungan N', didapatkan nilai N' yang lebih kecil dibanding $N\left(N^{\prime}<N\right)$ maka data yang digunakan sudah cukup dan tidak perlu dilakukan pengamatan tambahan untuk memenuhi datanya. Sehingga dapat disimpulkan data 3 pekerja sudah cukup mewakili subjek pengukuran dalam menentukan dimensi perancangan mesin. Perhitungan persentil pada data yang sudah seragam dan cukup untuk menentukan dimensi rancangan mesin dapat dilihat pada Tabel 4 berikut.

Tabel 4. Perhitungan persentil

\begin{tabular}{|c|c|c|}
\hline Pengukuran & Persentil 5th & Persentil 95th \\
\hline LB & 41,15 & 46,85 \\
\hline JTD & 66,79 & 74,54 \\
\hline TSB & 97,53 & 105,81 \\
\hline
\end{tabular}


Data lebar bahu digunakan untuk menentukan ukuran panjang rancangan mesin. Ukuran panjang pada rancangan mesin dipilih pada persentil 5 th yaitu $41,15 \mathrm{~cm}$. Pemilihan pada ukuran panjang ini dikarenakan agar pekerja yang berukuran paling kecil dapat dengan mudah mengoperasikan mesin selebar bahunya karena lebar mesin ini juga sebagai acuan ukuran dalam menentukan lebar tempat cetakan. Jika dipilih pada persentil 95th, dikhawatirkan pekerja yang berukuran kecil ini tidak mudah mengoperasikan mesin karena sulit menjangkau tempat cetakan yang memiliki lebar lebih dari lebar bahu tubuhnya.

Data jangkauan tangan ke depan digunakan untuk menentukan ukuran lebar pada rancangan mesin. Ukuran lebar rancangan mesin dipilih pada persentil 5 th yaitu $66,79 \mathrm{~cm}$. Ukuran lebar mesin juga menjadi acuan dalam menentukan lebar dari tempat cetakan. Sehingga ukuran persentil 5th dipilih agar saat dipindahkan dan diangkut oleh pekerja, tubuh pekerja memiliki keseimbangan yang baik karena tempat cetakan tidak melebihi ukuran pekerja yang memiliki ukuran kecil.

Data tinggi siku berdiri digunakan untuk menentukan ukuran tinggi pada rancangan mesin yang akan dibuat. Ukuran tinggi rancangan mesin dipilih pada persentil 5 th yaitu $97,53 \mathrm{~cm}$. Ukuran tinggi mesin ini dipilih pada persentil tersebut agar memudahkan pekerja yang beru kuran kecil dapat menaruh tempat adonan di atas mesin dengan nyaman sebab tenaga yang dikeluarkan lebih kecil dibanding pada saat tangan menjangkau tempat yang lebih tinggi dari tinggi sikunya saat berdiri.

Dari perhitungan didapatkan hasil ukuran mesin 41,15 x 66,79 x 97,53 cm. Kemudian rancangan mesin digambarkan seperti pada Gambar 2. Jenis bahan penyusun pada mesin bagian dalam akan digunakan material berbahan stainless steel. Bahan ini dipilih supaya dapat menjaga higienis adonan pada proses pengadukan dan pencetakan. Detail komponen penyusun pada rancangan mesin dapat dilihat pada Gambar 3 dan skema proses pengadukan dan pencetakan kue kembang waru dapat dilihat pada Gambar 4.

Proses pembuatan kue kembang waru mengalami peningkatan setelah menggunakan mesin yang dirancang. Ketika proses dilakukan secara manual, dibutuhkan waktu selama 10 menit untuk melakukan proses pengadukan dan proses penuangan untuk 15 cetakan. Namun, apabila dilakukan dengan menggunakan mesin, dalam waktu 10 menit kue dapat diproduksi sebanyak 20 cetakan. Dengan menggunakan perhitungan tingkat produktivitas, didapatkan peningkatan produktivitas setelah menggunakan mesin Duta Baru sebesar 25\%. Selain itu, waktu produksi menjadi lebih efisien dengan tingkat penurunan sebesar $25 \%$. 
Inovasi Mesin Duta Baru sebagai Pengaduk dan Pencetak Kue Kembang Waru di UMKM... Nia A'yunin, Firdaus Fitri, \& Febbyola Raflyani

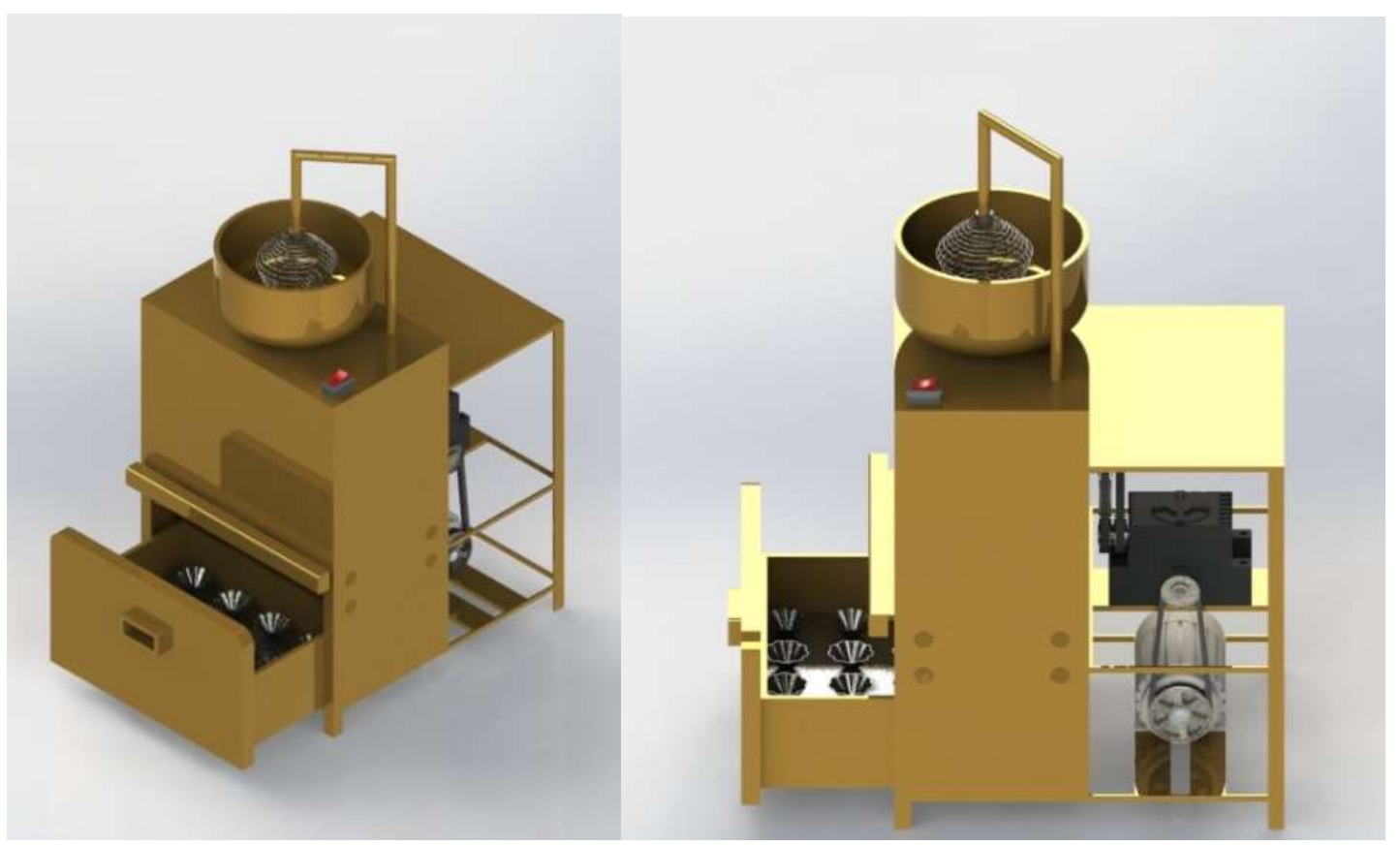

Gambar 2. Rancangan mesin Duta Baru

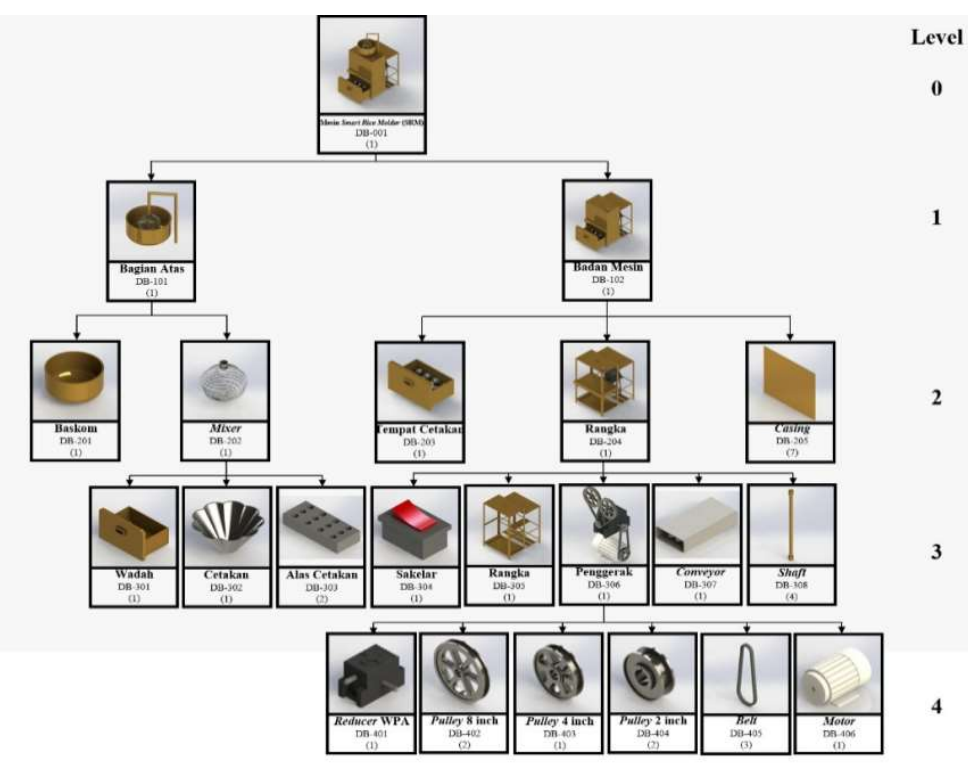

Gambar 3. Bill of component mesin Duta Baru 


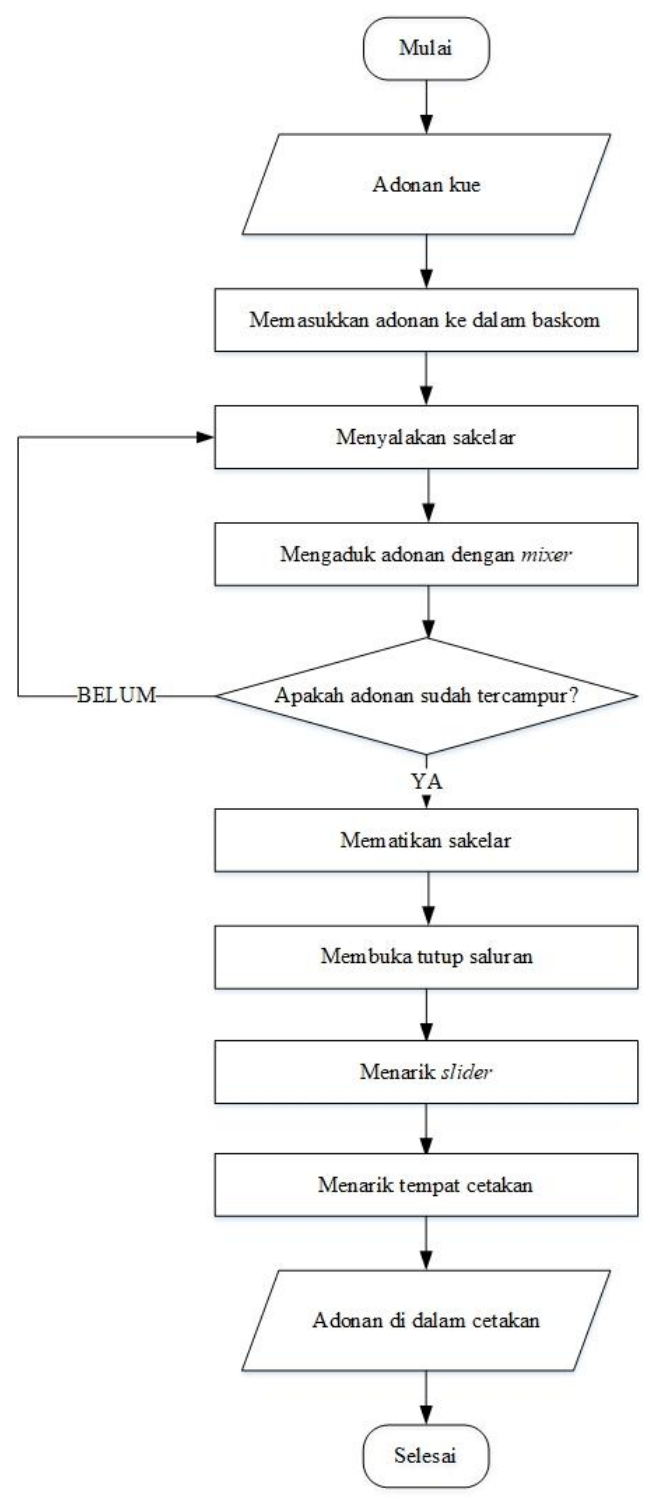

Gambar 4. Skema proses kerja mesin

Proses kerja mesin dimulai dengan adonan kue dimasukkan ke dalam baskom yang terletak di atas mesin Duta Baru. Kemudian sakelar yang berada di samping baskom dinyalakan, proses ini untuk menggerakkan mixer pada proses pengadukan adonan. Setelah adonan sudah tercampur rata, saklar dimatikan dan slider ditarik agar adonan dapat masuk ke proses pencetakan. Adonan yang sudah dicetak dapat dilihat dengan menarik wadah cetakan yang berada di bawah mesin, adonan ini yang sudah tercetak dan siap untuk dipanggang.

Prinsip yang digunakan dalam melakukan rancangan mesin Duta Baru yaitu gaya Lorentz. Gaya ini merupakan gaya yang ditimbulkan oleh arus listrik yang berada pada medan magnet. Gaya Lorentz timbul apabila sebuah penghantar dialiri arus listrik dan berada dalam medan magnetik. Gaya Lorentz memiliki arah gerak selalu tegak lurus dengan arah kuat arus listrik dan induksi magnetik yang ada. Arah gaya Lorentz mengikuti arah maju sekrup yang diputar ke arah medan magnet. Mesin penggerak yang digunakan dalam perancangan mesin ini menggunakan prinsip mixer. Komponen yang digunakan untuk menyusun mesin penggerak adalah BLDC (Brushless Direct Current Motor). Kelebihan dari BLDC yaitu memiliki efisiensi yang tinggi. Selain itu, BLDC membuat biaya perawatan menjadi lebih hemat, serta gesekan yang dihasilkan 
tidak menimbulkan polusi suara. Sedangkan kekurangan dari BLDC diantaranya adalah biaya pembuatan yang mahal serta sistem pengendalian yang rumit (Apresco, 2017).

Material yang digunakan dalam pembuatan mesin ini adalah stainless steel. Kelebihan dari stainless steel antara lain mudah dibersihkan, tahan lama serta penggunaannya dapat dalam jangka waktu yang panjang. Sedangkan kekurangan dari stainless steel adalah harganya yang mahal. Material kedua yang digunakan adalah plastik. Plastik ini digunakan sebagai bahan dasar dari baskom tempat adonan diaduk. Kelebihan dari plastic ini adalah ringan, murah, serta mudah dibersihkan kembali. Selain itu, bentuk adonan yang encer tidak akan lengket pada baskom ini. Baskom ini juga akan berputar sesuai dengan pengaturan dari mesin sehingga tidak perlu diputar menggunakan tangan.

$V$-Belt merupakan transmisi penghubung berbahan karet dan memiliki penampang trapesium. $V$-Belt yang digunakan adalah A32 dan A1000. Keuntungan menggunakan $V$-Belt adalah memiliki kemampuan untuk melindungi beban kejut ketika mesin dijalankan. V-Belt digunakan pada bagian pengadukan dan pencetakan adonan. Pulley merupakan komponen penting yang berfungsi sebagai alat untuk mentransmisikan daya dengan cara mengubah arah gaya yang diberikan, mengirim gerak, dan mengubah arah rotasi. Pulley yang digunakan yaitu pulley berukuran 2 inch, 4 inch, dan 8 inch. Bearing pada mesin berguna dalam mengurangi gesekan komponen-komponen yang saling bergerak dan saling menekan antara satu dengan yang lain. Bearing dipakai untuk menyangga perputaran poros. Tipe bearing yang digunakan adalah ball bearing. Keunggulan penggunaan ball bearing ialah permukaan gesek yang kecil (Kamaras \& Dimitrakopoulos, 2016).

\section{Kesimpulan}

Perancangan mesin Duta Baru digunakan untuk meringkas proses pengadukan dan pencetakan adonan dalam pembuatan kue kembang waru. Dengan menggunakan pendekatan antropometri pada data Lebar Bahu (LB), Jangkauan Tangan ke Depan (JTD), dan Tinggi Siku Berdiri (TSD) sebagai dasar dalam menentukan dimensi rancangan mesin. Dari hasil perhitungan, dimensi mesin memiliki ukuran panjang, lebar, dan tinggi yaitu 41,15 x 66,79 x 97,53 cm. Selain itu, produktivitas proses pembuatan kue kembang waru meningkat sebesar $25 \%$ dan terdapat penurunan waktu produksi sebesar $25 \%$.

Saran dalam penelitian ini adalah saat mengoperasikan mesin, pekerja dapat menggunakan sarung tangan agar adonan kue kembang waru tetap aman dari bakteri serta melakukan perawatan pada mesin secara rutin agar mesin selalu prima dan tidak menghambat produktivitas. Untuk penelitian selanjutnya, perancangan mesin dapat mempertimbangkan aspek-aspek lain selain dari ukuran tubuh manusia, seperti aspek konsumsi energi dan kondisi lingkungan kerja.

\section{Referensi}

Andi, S. (2007). Statistika dalam kajian deskriptif, Inferensi, dan Nonparametrik. Jakarta: Kencana Prenada Media Group.

Apresco, R. A. D. (2017). Perbandingan Unjuk Kerja Motor Brushless Direct Current dengan Brushed Direct Current pada Nogogeni Urban Konsep (Diploma dissertation, Institut Teknologi Sepuluh Nopember). 
Fitri, F., Raflyani, F., A'yunin, N., \& Prabuningrum, M. J. (2020). PERANCANGAN SMART RICE WASHER SEBAGAI PENCUCI DAN PEMISAH AIR CUCIAN BERAS DENGAN PENDEKATAN ERGONOMI-ANTROPOMETRI. In: Industrial Engineering Conference (IEC) 2020, $21 \quad$ November 2020, Yogyakarta. http://eprints.upnyk.ac.id/id/eprint/24003

Hendrawan, A., Sucahyowati, H., \& Laras, T. (2020). PENGARUH STRESS KERJA TERHADAP KREATIVITAS PADA TENAGA KERJA PADA UMKM DI WILAYAH BANTARSARI KABUPATEN CILACAP. AmaNU: Jurnal Manajemen dan Ekonomi, 3(1).

Husein, T., Kholil, M., \& Sarsono, A. (2009). Perancangan sistem kerja ergonomis untuk mengurangi tingkat kelelahan. Inasea, 10(1), 45-58.

Kamaras, K. \& Dimitrakopoulos, I. (2016). Vibration Analysis of Rolling Element Bearings using Spectral Kurtosis and Envelope Analysis: A white paper. Retrieved March 11, 2021, from https://fnt.com.cy/images/Advance Bearing_Monitoring FNT Jan 2016.pdf.

Leiwakabessy, P., \& Lahallo, F. F. (2018). Pembiayaan Usaha Mikro Kecil dan Menengah (UMKM) sebagai Solusi dalam Meningkatkan Produktivitas Usaha pada UMKM Kabupaten Sorong. Journal of Dedication to Papua Community (J-DEPACE), 1(1), 11-21. https://doi.org/10.34124/jpkm.v1i1.2

Nofirza, N., \& Infi, Z. (2011). PERANCANGAN ALAT BELAJAR DAN BERMAIN YANG ERGONOMIS DI TAMAN KANAK-KANAK ISLAM PERMATA SELAT PANJANG. Jurnal Ilmiah Teknik Industri, 10(1), 48-58. https://doi.org/10.23917/jiti.v10i1.1249

Putra, M. I. D., Vidawati, N. E., Melati, R., Raflyani, R., Ilfiana, L., \& Wibawa, T. (2019). Perancangan Mesin Penggoyang Wijen pada Industri Rumahan Onde-Onde di Dusun Gaduhan, Yogyakarta dengan Pendekatan Ergonomi Antropometri. In Seminar Nasional Teknik Industri 2019. Departemen Teknik Mesin dan Industri UGM. https://repository.ugm.ac.id/id/eprint/275334

Riduwan. (2009). Dasar-Dasar Statistika. Bandung: Alfabeta.

Tanan, C., \& Dhamayanti, D. (2020). Pendampingan UMKM dalam Pengelolaan Keuangan Usaha Guna Peningkatan Ekonomi Masyarakat di Distrik Abepura Jayapura. Amalee: Indonesian Journal of Community Research and Engagement, 1(2), 173-185. https://doi.org/10.37680/amalee.v1i2.408 